Journal of Management

Vol. 46 No. 2, February 2020 234-260

DOI: $10.1177 / 0149206318788434$

(C) The Author(s) 2018

Article reuse guidelines:

sagepub.com/journals-permissions

\title{
Do Group and Organizational Identification Help or Hurt Intergroup Strategic Consensus?
}

\author{
Jeanine Pieternel Porck \\ Oklahoma State University \\ Daan van Knippenberg \\ Drexel University \\ Murat Tarakci \\ Erasmus University Rotterdam \\ Nüfer Yasin Ateş \\ Bilkent University \\ Tilburg University \\ Patrick J. F. Groenen \\ Erasmus University Rotterdam \\ Marco de Haas \\ S-ray Diagnostics
}

Implementing strategy demands an organizationwide effort, where teams should not operate in isolation. A challenge many organizations face in implementing their strategy is eradicating silo thinking and creating shared understanding of strategy between interdependent teams-that is, intergroup strategic consensus. However, strategy process research is silent on how such intergroup strategic consensus can emerge. Drawing on social identity theory, we offer a lens to understand what influences the degree of intergroup strategic consensus. We unveil a tension between organizational and group identification such that organizational identification enhances intergroup strategic consensus, whereas group identification reduces it. Moreover, we hypothesize that high group identification crowds out positive effects of organizational identification on intergroup strategic consensus. Data from 451 intergroup relationships between 92

\footnotetext{
Acknowledgments: We would like to thank professor Franz Kellermanns, the Department of Management and Organization at the National University of Singapore, and Dr. T. C. Tac for their valuable comments on earlier versions. We also acknowledge with thanks the contributions of editor William Wan and three anonymous reviewers.

Corresponding author: Jeanine Pieternel Porck, Spears School of Business, Oklahoma State University, 373 Business Building, Stillwater OK, 74078, USA.
}

E-mail: jeanine.porck@okstate.edu 
teams within a service organization support these hypotheses. We replicate our results using 191 intergroup relationships between 37 teams from another organization. These results allow us to develop an understanding of intergroup strategic consensus, expand the conversation in strategy process research to between-team interdependencies, and challenge the assumption in management literature and practice that higher identification is always desirable.

Keywords: strategic consensus; intergroup relations; intergroup strategic consensus; social identity; strategy process; behavioral strategy

All teams in the organization, at all levels of the hierarchy, are responsible for putting the organization's strategy into action (Floyd \& Wooldridge, 1992b; Gagnon, Jansen, \& Michael, 2008; Ketokivi \& Castañer, 2004). Although each team has its own role and responsibilities during strategy implementation, teams do not operate in isolation. They are interdependent in their pursuit of the strategy, as their actions and decisions influence the actions and decisions of other teams (Noda \& Bower, 1996). Strategy process research has long recognized the importance of strategic consensus, the shared understanding of the organization's strategic priorities, for successful strategy implementation. Strategic consensus allows those responsible for strategy implementation to act in a way that is consistent with the actions of others and consistent with the intended strategic direction of the organization (Kellermanns, Walter, Lechner, \& Floyd, 2005; Walter, Kellermanns, Floyd, Veiga, \& Matherne, 2013). Accordingly, the premise of strategic consensus research is that consensus prevents coordination issues and improves cooperation within the organization (Cronin \& Weingart, 2007; Floyd \& Wooldridge, 1992a; Kellermanns, Walter, Floyd, Lechner, \& Shaw, 2011).

However, a growing body of evidence suggests that many organizations are faced with between-team issues that hinder strategy implementation (Balogun, 2006; Floyd \& Wooldridge, 1992b; Raes, Heijltjes, Glunk, \& Roe, 2011). That is, strategic priorities are not achieved because teams think only about their own "silo" or because they are working toward different strategic priorities due to disparate understandings of what needs to be done (e.g., Balogun, 2006; Balogun \& Johnson, 2005). While teams need to have a shared understanding of the coherent and mutual action required from them, strategic consensus research has almost exclusively studied consensus at the within-group level (Kellermanns et al., 2005; Tarakci, Ates, Porck, van Knippenberg, Groenen, \& de Haas, 2014). The lack of attention to intergroup strategic consensus represents a significant blind spot, in that it ignores the complexities of aligning and coordinating activities and resources between groups. This is problematic, because intergroup dynamics cannot be assumed to parallel within-group dynamics (van Knippenberg, 2003). Moreover, each team may construe its own understanding of the organizational strategy, which may or may not be in line with other teams' understanding of strategic priorities. This suggests that we need to develop a comprehensive understanding of what influences the degree of shared understanding of strategic priorities between interdependent teams - intergroup strategic consensus.

To that end, we draw on social identity theory - the dominant theoretical perspective in research in intergroup relations (Hogg, van Knippenberg, \& Rast, 2012; Pettigrew, 1998; Tajfel \& Turner, 1979), which captures how identification with a social group renders certain 
objectives and norms more salient to members of that group (Ashforth \& Mael, 1989; Hogg $\&$ Terry, 2000). Organizations provide multiple potential nested foci of identification (most prominently the team and the organization) that shape intra- and intergroup dynamics (Hornsey \& Hogg, 2000; Mummendey \& Wenzel, 1999). Strong organizational identification is linked positively to intergroup relations (Ashforth \& Mael, 1989; van Knippenberg \& van Schie, 2000). Conversely, strong group identification is linked positively to intragroup relations but negatively to intergroup relations, because it may cause an "us-versus-them" mind-set or "silo mentality" (Dovidio \& Gaertner, 2010; van Knippenberg, 2003). Integrating these two propositions, the dual-identity literature argues that any potential negative consequences of strong group identification can be compensated by strong organizational identification (Gaertner et al., 1999; Gaertner, Dovidio, \& Bachman, 1996). Accordingly, achieving both strong group and organizational identification is considered a "best practice" both in the management literature and practice (Erickson, 2010; Gratton \& Erickson, 2007; Reitzig \& Sorenson, 2013).

However, recent advances in social identity theory suggest that such a dual identity is hard to achieve (Hogg et al., 2012), and it is uncertain what its outcomes would be in relation to achieving intergroup strategic consensus. Despite claims about positive intergroup outcomes, research on dual identity has mostly examined intergroup biases among independent standalone teams and has barely examined actual intergroup outcomes of interdependent teams (cf. Gaertner et al., 1999). In contrast to this positive stance, recent advances in intergroup relations research suggest that the combination of strong group and organizational identification invites a process of in-group projection (Hogg et al., 2012; Wenzel, Mummendey, \& Waldzus, 2007). Here the overarching identity (i.e., the organizational identity) is subjectively construed as an extension of the group identity and invites negative responses to other teams as deviating from this construed overarching identity (Mummendey \& Wenzel, 1999). In other words, ingroup projection causes teams to view their own team as prototypical of the organization and to regard other teams negatively because they do not adhere to this groupbased prototype.

We build on these recent developments in the literature to offer a social identity perspective on intergroup strategic consensus. We challenge the dual-identity perspective and the overall positive stance in the management literature that favors high levels of both organizational and group identification (cf. Gaertner et al., 1999; Richter, West, van Dick, \& Dawson, 2006). Instead, we hypothesize that strong group identification can hurt intergroup strategic consensus because it can lead to a closing of the mind toward communications from other teams (Ashforth \& Mael, 1989; Dovidio \& Gaertner, 2010; Hogg \& Terry, 2000), even when organizational identification is strong. This builds on the notion that this combination of strong identifications can invite ingroup projection and associated negative attitudes toward other teams. This will reduce team members' attention to the "bigger picture" and their perceived interdependence with other teams. Therefore, we hypothesize that organizational identification has a positive influence on intergroup strategic consensus only when group identification is low. Only then may organizational identification heighten awareness of strategic priorities and the need to coordinate with other teams, which will have a positive effect on intergroup strategic consensus.

We contribute to the literature in several ways. First, we contribute to strategy process research by offering a social identity perspective on intergroup strategic consensus. Introducing this perspective allows us to understand the phenomenon of intergroup strategic 
consensus and answers calls to ground strategic management in realistic psychological assumptions, along the lines of behavioral strategy (Hutzschenreuter \& Kleindienst, 2006; Jarzabkowski \& Spee, 2009; Powell, Lovallo, \& Fox, 2011). Second, our investigation of intergroup strategic consensus expands the focus in strategy process research to betweenteam interdependencies and contributes to the emerging stream of strategy process research on the challenges associated with aligning strategic efforts throughout the organizational hierarchy (Floyd \& Wooldridge, 1992a; Raes et al., 2011). Third, we provide a meaningful extension of the work on social identity in the management literature (Ashforth \& Mael, 1989; Riketta \& van Dick, 2005; van Knippenberg \& van Schie, 2000) by arguing and showing in two studies that for intergroup strategic consensus, group identification is a negative influence - and a negative influence that cannot be countered by organizational identification. Thus, our study challenges the assumption in management research and practice that higher identification is always desirable (cf. Erickson, 2010; Gratton \& Erickson, 2007) and broadens the basis for the further study of intergroup relations in organizations (cf. Hogg et al., 2012; Wenzel et al., 2007).

\section{Theoretical Background and Hypotheses}

\section{Strategic Consensus Between Interdependent Teams}

During the strategy process, teams each have their respective responsibilities, but to put strategy into action, it is also crucial that "different units, functions and levels support the company strategy - and one another" (Lingle \& Schiemann, 1996: 59). Ideally, all teams in the organization are aligned with the strategy as formulated by top management and would thus be strategically aligned with each other (cf. Lee \& Puranam, 2016). However, such perfect strategic alignment is very hard, if not impossible, to achieve, judging by the numerous studies showing that problems occur between teams during the strategy process (e.g., Balogun \& Johnson, 2005; Raes et al., 2011). For example, there is a vast literature focused solely on investigating the often-combative relations between marketing and manufacturing (e.g., Crittenden, Gardiner, \& Stam, 1993; St John \& Rue, 1991). These studies indicate that a core cause for problems is that these interdependent teams have different understandings of strategy (St John \& Rue, 1991). This suggest that to develop an understanding of the complexities of aligning strategic efforts between interdependent teams, we need an understanding of what influences the shared understanding of strategic priorities between interdependent teams.

To do so, we define intergroup strategic consensus as the degree of shared understanding of strategic priorities between interdependent teams at the top, middle, and lower levels of an organization. This builds on the definition of within-group strategic consensus (Kellermanns et al., 2005, 2011), broadening it to an intergroup level. So far, research on strategic consensus has investigated consensus within teams and has examined mostly the top management of the organization because it is seen as the primary constituent of the strategy process (Kellermanns et al., 2005; Tarakci et al., 2014). Our definition of consensus involves interdependent teams at all levels of the organization, however, to reflect the recent shift in strategy process research to focus on all levels of the organizational hierarchy (González-Benito, Aguinis, Boyd, \& Suárez-González, 2012; Kellermanns et al., 2005).

The premise of our focus on intergroup strategic consensus is that during strategy implementation, intergroup strategic consensus prevents teams from working toward different 
strategic priorities, prevents intergroup coordination issues, and improves intergroup cooperation (cf. Cronin \& Weingart, 2007; Floyd \& Wooldridge, 1992a; Kellermanns et al., 2005). Our focus on intergroup strategic consensus is not to argue against the possibility that strategic dissent during strategy formulation may stimulate strategic decision quality (Dooley \& Fryxell, 1999; but see Samba, van Knippenberg, \& Miller, 2018) or against the value of emerging insights that would suggest revisions of the strategy (Lee \& Puranam, 2016). Rather, we focus on strategic consensus as an outcome that serves organizations, where top management, or a wider spectrum of stakeholders, has formulated and agreed on a strategy and seeks to implement this. Intergroup strategic consensus at all levels of the organization would be in service of this implementation.

The unit of analysis for intergroup strategic consensus is the intergroup dyad, the relationship between two teams that depend upon each other for materials, resources, and/or information for the accomplishment of strategic priorities. To capture intergroup consensus, then, we need to focus on all relevant (i.e., interdependent) dyadic intergroup relations within an organization. This goes beyond earlier intergroup research that either asked groups only about their intergroup relations with respect to one specific other group (e.g., Richter et al., 2006; St John \& Rue, 1991) or asked managers to assess an overall cross-functional outcome (e.g., Ketokivi \& Castañer, 2004). Because teams can be dependent upon more than one other team, teams can be part of multiple intergroup dyads. It is because the quality of these work relationships can vary that one must focus on strategic consensus at the intergroup dyad level and not at the group level.

\section{A Social Identity Perspective on Intergroup Strategic Consensus}

Recognizing that the intergroup dyad is the appropriate level of analysis for the study of intergroup strategic consensus also positions this study in intergroup relations research (e.g., van Knippenberg, 2003). Social identity theory, the leading conceptual perspective in intergroup relations research, is much more broadly applied today than to just intergroup relations (Hogg et al., 2012; van Knippenberg, 2003). Social identity theory argues that team members gain a sense of their identity from contrasting their team with other groups (Ashforth, Harrison, \& Corley, 2008), which informs how to perceive and approach other groups (Tajfel $\&$ Turner, 1979). Yet, the theory's primary application in management research has been on individual and intragroup processes rather than intergroup relations (Haslam, 2004).

Social identity theory centers around the fact that people perceive themselves to a greater or lesser extent in terms of their membership of social groups - their social identity (i.e., the sense of "we"; Ashforth \& Mael, 1989). Organization members can identify with multiple social groups and can holistically define themselves in terms of multiple identities (Ashforth et al., 2008). The most relevant organization-based identifications are typically identification with the organization as a whole (i.e., organizational identification) and identification with the team, work group, or department in which most of the day-to-day job activities are embedded (i.e., group identification; see van Dick, van Knippenberg, Kerschreiter, Hertel, \& Wieseke, 2008).

Group and organizational identification are generally associated with positive outcomes, such as positive work attitudes, performance, citizenship, and reduced turnover (see the meta-analysis by Riketta \& van Dick, 2005). Many of these outcomes are driven by the fact that through identification, the group's interests are experienced as self-interest (i.e., "our" 
interest; Ashforth \& Mael, 1989; van Knippenberg, 2000). This is particularly relevant from the perspective of strategic consensus, because identification can focus attention on and motivate (extra) efforts and cooperation to realize collective goals (De Cremer, van Knippenberg, van Dijk, \& van Leeuwen, 2008), and strategic priorities in effect are collective goals.

However, even when the positive effects of group identification are evident when the focus is on intragroup outcomes, they may not generalize to intergroup outcomes, like intergroup strategic consensus. Despite being primarily applied to individual and intragroup outcomes in management research, social identity theory offers the primary perspective to understand intergroup relations in organizations. The dominant intragroup focus, however, is consistent with a more general trend to recognize the importance of intergroup relations in organizations but to have little research follow-up on this recognition (Hogg et al., 2012; van Knippenberg, 2003), as is seen in both the social identity and strategy process literatures. The question how group and organizational identifications affect intergroup consensus thus is particularly relevant for both these literatures. This holds all the more so because we cannot simply derive the answer to this question from the dominant focus on individual-level and intragroup processes in social identity research. Addressing this issue, in the following sections we outline our social identity perspective on intergroup strategic consensus and associated hypotheses.

\section{Organizational Identification and Intergroup Strategic Consensus}

To unite different teams in pursuit of a collective vision or strategy in organizational settings, researchers have long stressed the positive influence of organizational identification (Kramer, 1991; Riketta \& van Dick, 2005). Organizational identification centers attention on organizational norms and goals (Ashforth \& Mael, 1989; van Knippenberg, 2000). Strong organizational identification is likely to make team members think and act in accordance with the organization and its overarching goals (cf. Gaertner et al., 1999; Richter et al., 2006). We propose that organizational identification may therefore foster strategic consensus by inspiring attention to and internalization of the organization's strategic objectives.

Another reason why organizational identification may be beneficial for intergroup strategic consensus is that it is conducive to a shared sense of purpose with other teams (Ashforth \& Mael, 1989; Kramer, 1991; van Knippenberg, 2003) and leads team members to recognize other teams as "being on the same team." Because organizational identification orients team members toward a sense of "we, the organization" (van Knippenberg \& van Schie, 2000), it can create higher motivation to go beyond their own silo and work toward strategy implementation with other teams in the organization. In other words, stronger organizational identification makes teams more aware of the fact that their team operates not in isolation but as part of a larger whole in which different teams complement and build on one another's efforts. This heightened awareness of shared strategic priorities and the need to coordinate and cooperate with other teams will have a positive effect on intergroup strategic consensus. Therefore, we propose the following:

Hypothesis 1: Organizational identification in an intergroup dyad is positively related to intergroup strategic consensus. 


\section{Group Identification and Intergroup Strategic Consensus}

Although the teams literature extols group identification (Riketta \& van Dick, 2005), various social identity scholars outside of the management domain have warned that group identification may have negative consequences when it comes to intergroup relations (Brewer, 1997; Pettigrew \& Tropp, 2006). Building on this research, we argue that group identification may have a negative impact on intergroup strategic consensus for two reasons.

First, teams develop their sense of identity by making comparisons between their own team and other teams (Dovidio \& Gaertner, 2010; Tajfel \& Turner, 1986). In this process of making comparisons, teams strive to be separate from and superior to other teams (Dovidio \& Gaertner, 2010; Tajfel \& Turner, 1986). These behaviors may orient team members toward perceiving intergroup relations in "us-versus-them" terms (Pettigrew \& Tropp, 2006; van Knippenberg, 2003) and may reduce attention to the superordinate strategic priorities that teams ought to share (the "bigger picture"). This behavior has been observed in several strategy process studies (e.g., Balogun, 2006; Balogun \& Johnson, 2005; Reitzig \& Sorenson, 2013). For example, in a longitudinal, ethnographic study of strategy implementation, Balogun (2006: 37) explains, "Middle manager diaries contained extensive entries on the development of a 'them and us situation' between the Core division and the other two divisions. Interdivisional tensions were appearing with a sense of competition rather than cooperation." Such a competitive mind-set caused by strong group identification is likely to harm intergroup strategic consensus.

Second, strong group identification is associated with in-group favoritism and a reduced willingness to cooperate and communicate with other teams (e.g., Ashforth \& Mael, 1989; Hogg \& Terry, 2000). We know from research on sensemaking and cognition (see Balogun \& Johnson, 2005) that members' interpretations of change plans, such as strategy, are shaped by their interactions with others. As team boundaries are strengthened by group identification, people tend to interact mostly with their team, which might place an emphasis on strategic priorities that are most closely aligned with the responsibilities of the team and lead to less attention for other seemingly "unrelated" strategic priorities (cf. Ketokivi \& Castañer, 2004). Moreover, as team boundaries strengthen, so do the negative perceptions of other teams, which may reduce transfer of information across team boundaries. When group identification reduces open-minded communication outside the boundaries of the own team, it may also reduce opportunities to create a shared understanding of strategy between teams. We propose the following:

Hypothesis 2: Group identification in an intergroup dyad is negatively related to intergroup strategic consensus.

\section{Interaction Between Group and Organizational Identification}

A tension between the conflicting effects of group and organizational identification on intergroup outcomes is well established conceptually and empirically in the social psychological intergroup relations literature (Hogg et al., 2012; Kramer, 1991; Mummendey \& Wenzel, 1999). The literature on the influence of the combination of group and organizational identification, however, is sparse and scattered (Ramarajan, 2014). As such, not all findings may generalize to intergroup strategic consensus among teams. For instance, the 
literature on dual identity (i.e., high group and organizational identification) has argued that it is better for intergroup perceptions when both the group and superordinate, organizational identity are emphasized simultaneously, because people may respond negatively to attempts to emphasize only a superordinate identity (Gaertner et al., 1999; Hornsey \& Hogg, 2000). Our concern here, however, is not with the influence of an external emphasis on one or both identities but in the joint influence of group and organizational identification as psychological states. Similarly, Richter and colleagues (2006) examined the role of leader's dual identity, but leaders are more on the intergroup interface than group members (cf. Hogg et al., 2012), and as such, leader identification effects may not generalize to group member identification effects.

To address the tension between the conflicting effects of group and organizational identifications, more recent insights in in-group projection provide a powerful conceptual tool (Hogg et al., 2012; Wenzel et al., 2007). Research in in-group projection suggests that the combination of strong group and superordinate (i.e., organizational) identification invites a process of in-group projection in which the overarching identity is subjectively construed as reflecting the group identity (Mummendey \& Wenzel, 1999; Wenzel et al., 2007). Such ingroup projection leads team members to view their own team as a valued and representative prototype of the organization but to judge other teams more negatively because they do not conform to that group-based perception of the organization. Thus, other teams are viewed as deviating from what is normative about the organizational identity and are therefore evaluated negatively.

For intergroup strategic consensus, the notion of in-group projection implies that the combination of strong group and organizational identification is bad for intergroup consensus. When both group and organizational identification are high, in-group projection invites negative responses to other groups. These responses hinder intergroup consensus for two reasons. First, creating shared intergroup understanding requires rapport, and in-group projection is associated with lower rapport. Second, in-group projection invites the team to remain focused on the own team, reducing open-minded communication outside the boundaries of the own team. We propose that these influences of group identification shape the influence of organizational identification, such that organizational identification primarily stimulates intergroup strategic consensus with lower levels of group identification. Only with lower levels of group identification will organizational identification focus attention on strategic priorities and build the motivation to go beyond the own silo. We propose the following:

Hypothesis 3: Group identification in an intergroup dyad moderates the relationship between organizational identification and intergroup strategic consensus such that the relationship between organizational identification and intergroup strategic consensus is positive when group identification is low and negative when group identification is high.

\section{Methods}

To test our hypotheses, we conducted a main study and a replication study, following the recent calls in the strategic management literature for robust findings (Bettis, Helfat, \& Shaver, 2016). Following guidelines by Bettis et al. (2016), we aimed to replicate our research model in a similar context (i.e., another organization with a clear, deliberate strategy and highly interdependent teams) using the same research design. This replication allows us to 
compare the findings and demonstrate that they are not specific to a particular organization and enhances the confidence in the validity of our results.

\section{Organizational Context Main Study}

Our main study was conducted in a large technical service company from Western Europe that specializes in the transportation of gas and electricity to households through its infrastructure. The environment of the company can be characterized as stable due to government regulations and a limited number of competitors. The organization provided an ideal setting, because it was in the strategy implementation phase - that is, the transformation of strategy into collective action with minimal distortion (Lee \& Puranam, 2016) — during our data collection. The organization's strategy formulation process was largely determined by the top management team (TMT), which had formulated long-term strategies to match its stable environment, resulting in this organization's seven strategic priorities. Due to the confidentially agreement, we can present only shortened versions of the seven strategic priorities of the company: innovativeness, regulation, reliable network, safety, expert staff, organization structure, and certification. The company also offered a good site for our research because the company consists of highly task-interdependent work groups spread over various locations, with different areas of expertise. The work by these groups complements work by others and must be integrated to ensure a reliable and safe distribution network, which is of the utmost importance for this organization. This thus calls for strategic consensus between interdependent work groups, as was highlighted by the CEO during the intake interviews: "So, we need all employees to understand the bigger picture, to understand that our client is number one and thus, that just doing your own job in splendid isolation, and doing an OK job on that, is not enough."

\section{Data Collection}

Employee and team data for our main study were collected with the relevant firm records, including human resources data, job descriptions, and the formal organizational chart. ${ }^{1} \mathrm{On}$ the basis of a number of initial interviews, we developed an online employee survey. This survey was administered to the TMT and all work groups. Following the recommendations by Podsakoff, MacKenzie, and Podsakoff (2012), we launched the survey with an e-mail signed by the CEO, which included an explanation of the importance of the survey, clear instructions, and a personalized link to the survey website. Two reminders and a final announcement were sent to increase response rate. We indicated at the start of the survey that respondent anonymity was protected and that only aggregated results would be shared with the organization (as recommended by Podsakoff, MacKenzie, Lee, \& Podsakoff, 2003). In all communications, we highlighted the confidentiality of individual responses.

The survey was sent to all 109 work groups in the organization (low, middle, and top levels) and the TMT (891 respondents in total). The response rate was $74 \%$. We separated the TMT from the sample because it is the formal owner of the strategy and therefore its understanding of the strategy is different in nature. In addition, separating the TMT enabled a supplementary analysis of dyads' strategic alignment with the TMT. We further discarded 17 work groups: five groups that had less than $50 \%$ response rate, because the remaining responses may not represent the group as a whole (Van Ophem, Stam, \& van Praag, 1999), 
and 11 groups that had only one or two respondents, which prior research does not recommend for measuring strategic consensus (Tarakci et al., 2014). The discarded teams did not differ from the teams in the sample with respect to any of the study's independent variables (largest $t$ value was $1.35, p=.182$ ). Our final sample consisted of 92 teams, ranging in size from 3 to 15 members, with an average of 6.63 persons per group and a mean within-group response rate of $80.4 \%$. The mean age of the participants was $45.3(S D=10.7) ; 79.6 \%$ were male. Participants had on average 22.8 years $(S D=12.2)$ of work experience; $48.0 \%$ had a bachelor's degree or higher.

\section{Identifying the Intergroup Dyads}

Our unit of analysis is the intergroup dyad - that is, a pair of teams that are interdependent. To identify which work groups formed these intergroup dyads, we determined the dependence between teams in the dyad following a two-step procedure. First, respondents were asked to indicate the names of their colleagues upon whom they most depend for materials, resources, and/or information to be able to do their work properly (Ibarra, 1993). An auto-complete form, including a stored list of all employees that allowed respondents to select their answers from the list, facilitated this question. In the second step, we aggregated these connections to the team level such that for dependence links between work groups, the $i$, $j$ th cell was coded 1 if one of the work group members in $i$ indicated a tie with one of the members of team $j$, or vice versa.

For the 92 work groups, 451 intergroup dyads were identified, that is, work groups had an average of four to five relationships with other work groups, making them part of four to five intergroup dyads. We study the role of group identification and organizational identification on intergroup strategic consensus within these 451 intergroup dyads. Figure 1 provides a depiction of 15 of the 451 intergroup dyads in this organization.

\section{Measures}

Following recommendations on dealing with common method variance (Podsakoff et al., 2003, 2012; Spector, 2006), all measures in this study relied on established scales from the literature, used response scales with every point labeled, and balanced positive and negative items to eliminate scale ambiguity and reduce social desirability bias. The use of different methods of data collection in the survey eliminated common scale properties.

Degree of intergroup strategic consensus. We measured strategic consensus with respect to the organization's seven strategic priorities as formulated by the TMT of the company. In line with recommendations in the strategy literature (Kellermanns et al., 2005; Walter et al., 2013; West \& Schwenk, 1996), we choose to have a context-specific measurement for our dependent variable. We do so based on the assumption that the environment of the organization has certain properties to which an organization can adapt by its choice of strategy (see Lee \& Puranam, 2016). In addition, Ketokivi and Castañer (2004) have shown that communication of strategy to employees during the strategy process may enhance goal convergence.

We asked respondents to rank the seven strategic priorities in terms of importance (the typical assessment of strategic consensus; Kellermanns et al., 2011; Tarakci et al., 2014). This follows Boyer and Pagell's (2000) recommendation to use rankings over ratings to 
Figure 1

\section{Depiction of a Selection of 15 of the 451 Intergroup Dyads in This Organization}

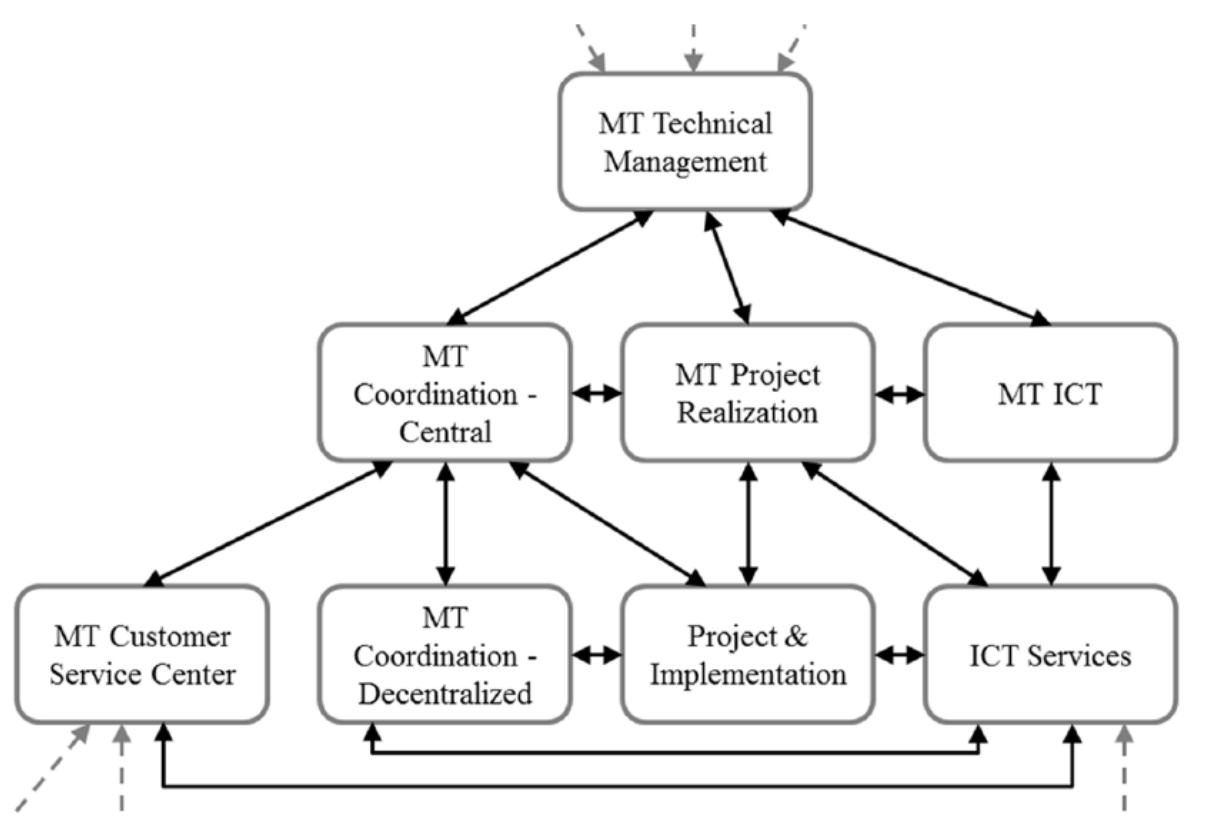

Note: Each black arrow depicts an intergroup dyad, a relationship between a pair of interdependent work groups. $\mathrm{MT}=$ management team. From Figure 1, it can, for instance, be inferred that MT Information and Communications Technology (MT ICT) is part of three intergroup dyads, namely, (a) the relationship between MT Technical Management and MT ICT, (b) the relationship between MT ICT and MT Project Realization, and (c) the relationship between MT ICT and ICT Services.

encourage respondents to make the hard choices regarding what is the most important strategic priority (as ratings allow or tempt respondents to make everything equally important).

We adopted Tarakci et al.'s (2014) $r$ measure to operationalize the degree of intergroup strategic consensus. Here, first, the overall view of each group in terms of its rank order of the strategic priorities is determined, that is, a prototypical team member for each group is determined. Then, the degree of intergroup strategic consensus, $r(A, B)$, is measured as the correlation of the scores of the strategic priorities for the prototypical team members of groups $A$ and B. An $r(\mathrm{~A}, \mathrm{~B})$ of 1 indicates full intergroup consensus, and an $r(\mathrm{~A}, \mathrm{~B}) \approx-1$ indicates low intergroup consensus (for further methodological details, see Tarakci et al., 2014). ${ }^{2}$

Organizational identification in the dyad. Organizational identification was measured by five items of the organizational identification measure from Mael and Ashforth (1992; cf. van Knippenberg \& van Schie, 2000) using a 5-point Likert-type scale. This scale had satisfactory reliability $(\alpha=.76)$. Sample items include "When someone criticizes [name of organization], it feels like a personal insult" and "When I talk about [name of organization], 
I usually say 'we' rather than 'they."' The mean $r_{w g}$ value for organizational identification was 0.93 and justified aggregation to the group level. Because this variable originates at the team level, it was subsequently aggregated to the dyadic level by calculating the average organizational identification in each dyad, because the organizational identification of both groups is equally important (cf. Chen, Mathieu, \& Bliese, 2004; Klein \& Kozlowski, 2000). ${ }^{3}$

Group identification in the dyad. Group identification was measured by the same five items of the identification measure from Mael and Ashforth (1992) as were used for organizational identification but this time with the work group rather than the organization as target (van Knippenberg \& van Schie, 2000). The scale had good reliability $(\alpha=.80)$. Sample items include "When someone criticizes my work group, it feels like a personal insult" and "When I talk about this work group, I usually say 'we' rather than 'they." The mean $r_{w g}$ value for group identification was 0.92 and confirmed aggregation to the group level. It was subsequently aggregated to the dyadic level by calculating the average group identification in each dyad, since the level of group identification of both groups is equally important.

Control variables. To rule out possible alternative explanations, we controlled for several covariates. First, we controlled for a communication link between work groups in the dyad, because creating intergroup strategic consensus can be more difficult when teams do not communicate. To establish a communication link, respondents were asked, "Please indicate the names of your colleagues with whom you most often discuss what is going on in the organization" (Ibarra, 1993). Respondents were told they could choose colleagues from both within and outside their group, using the auto-complete form provided. We aggregated the results, where for communication links between groups, the $i$, $j$ th cell was coded 1 if one of the team members in team $i$ indicated a tie with one of the members of team $j$, or vice versa.

Second, we controlled for structural link between work groups in the dyad, because organizational structure already might impose intergroup contact, leading to intergroup consensus. For structural link in a dyad, the $i$, $j$ th cell was coded 1 if the work groups were linked in the formal organizational chart of the organization, provided by the human resources department.

Third, we controlled for the influence of the work groups in the dyad being the same level, because one group may influence the strategic understanding of another, particularly if the latter is lower ranked (Tsai, 2002). To do so, the $i$, $j$ th cell was coded 1 if the work groups consisted of two teams of the same level and 0 if the intergroup dyads were cross-level. Of all 451 dyads, $35.5 \%$ consisted of teams from the same level; the other $64.5 \%$ were cross-level.

Fourth, we controlled for intergroup elaboration in the dyad-the exchange and careful consideration of distributed information between groups (van Knippenberg, De Dreu, \& Homan, 2004) - and strategic involvement in the dyad, because work groups that generally elaborate more with other groups or that are more involved in the strategy might consequently be more aligned with the organization's strategy and thereby with other groups. Intergroup elaboration was operationalized through four items adapted from Raver and van Knippenberg (2007) using a 5-point Likert-type scale $(\alpha=.75)$, and strategic involvement 
was operationalized through five items adapted from Wooldridge and Floyd (1990) using a 5-point Likert-type scale $(\alpha=.94)$. Both variables were translated to the relational level by calculating the average strategic involvement and average intergroup elaboration for each dyad.

Finally, we controlled for within-group consensus in the dyad, which is determined with the $\alpha$ measure proposed by Tarakci et al. (2014). If within-group strategic consensus is high, the $\alpha$ measure will be close to 1 , but when consensus is low, the $\alpha$ measure will be close to 0 . We controlled for within-group strategic consensus because a dyad might have high between-group consensus not because of the identification processes studied here but because they both happen to have high within-group consensus. We subsequently calculated the average within-group consensus for each intergroup dyad.

\section{Analysis}

In our study, all the variables concern dyadic relationships and form a matrix of observations with the work groups as row and column entities. Because these relational matrix-level data are autocorrelated and systematically interdependent, ordinary least square analysis or multilevel regression analysis is not appropriate (Dekker, Krackhardt, \& Snijders, 2007). Instead, we used the multiple regression quadratic assignment procedure (MRQAP; Borgatti, Everett, \& Freeman, 2002; Dekker et al., 2007; Krackhardt, 1988), which is specifically developed for relational data analysis and takes into account the row/column interdependencies in the data set (Krackhardt, 1988; Tsai, 2002). Moreover, MRQAP is robust to multicollinearity (Dekker et al., 2007) and adjusts for autocorrelations (Dekker et al., 2007; Kilduff \& Krackhardt, 1994). In addition to enabling the analysis of relational data, the results from MRQAP with respect to parameter estimates can be interpreted in a fashion similar to a traditional (multiple) regression analysis (Dekker et al., 2007). The application of MRQAP to the study of intergroup relations is new and holds a key position in our study of intergroup strategic consensus.

\section{Results}

We first conducted multilevel confirmatory factor analyses (CFA) to test the distinctiveness of group and organizational identification and performed a chi-square difference test to compare the one- and two-factor solutions. We observed that organizational and group identification loaded in two separate factors in a two-factor solution. The $\chi^{2}$ difference test revealed that the two-factor solution offered significantly better fit, $\Delta \chi^{2}(9)=242.42, p<$ .001 . These results ascertain the distinctiveness of group and organizational identification.

Table 1 reports means, standard deviations, and quadratic assignment procedure correlations for the key variables used in this research. We observe that group and organizational identification are positively correlated $(r=.61, p=.000)$ and that there is a significant correlation between group identification and intergroup strategic consensus in the hypothesized direction $(r=-.26, p=.005)$ but not between organizational identification and intergroup strategic consensus $(r=-.04, n s)$. We also observe a significant positive correlation between dependence between teams and control variables communication $(r=.63, p=.000)$, structural link $(r=.34, p=.000)$, teams in dyad are same level $(r=.05, p=.028)$, intergroup 


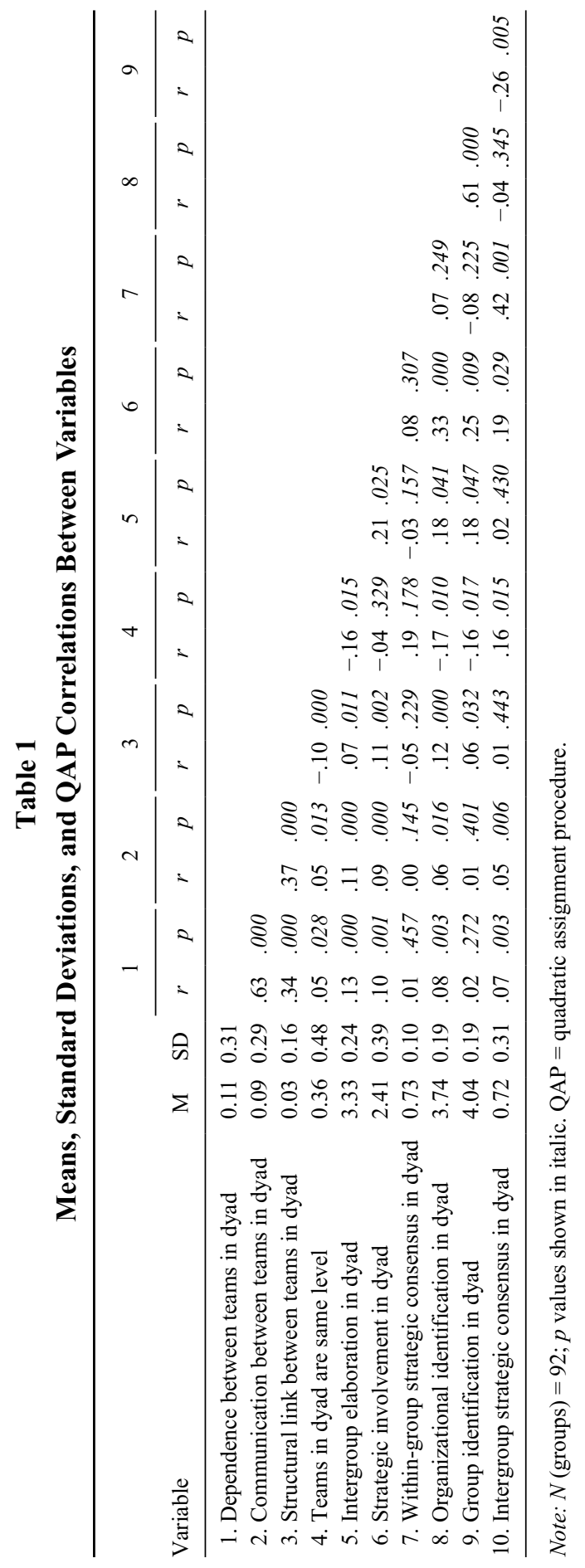


Table 2

The Effect of Organizational and Group Identification on Intergroup Strategic Consensus, MRQAP Regression Results

\begin{tabular}{|c|c|c|c|c|c|c|c|c|c|c|c|c|}
\hline \multirow[b]{2}{*}{ Variable } & \multicolumn{4}{|c|}{ Step 1} & \multicolumn{4}{|c|}{ Step 2} & \multicolumn{4}{|c|}{ Step 3} \\
\hline & $b$ & $S E$ & $\beta$ & $p$ & $b$ & $S E$ & $\beta$ & $p$ & $b$ & $S E$ & $\beta$ & $p$ \\
\hline Intercept & .77 & .00 & & .000 & .77 & .00 & & .000 & .79 & .00 & & .00 \\
\hline \multicolumn{13}{|l|}{ Controls } \\
\hline $\begin{array}{l}\text { Communication between teams in } \\
\text { dyad }\end{array}$ & .05 & .01 & .12 & .001 & .04 & .01 & .10 & .002 & .04 & .01 & .09 & .002 \\
\hline Structural link between teams in dyad & -.05 & .02 & -.10 & .005 & -.04 & .02 & -.07 & .025 & -.04 & .02 & -.07 & .025 \\
\hline Teams in dyad are same level & -.03 & .01 & -.07 & .008 & -.04 & .01 & -.09 & .001 & -.03 & .01 & -.08 & .005 \\
\hline Intergroup elaboration in dyad & -.04 & .04 & -.04 & .146 & -.01 & .03 & -.02 & .335 & -.01 & .03 & -.01 & .378 \\
\hline Strategic involvement in dyad & -.05 & .02 & -.10 & .006 & -.02 & .02 & -.03 & .227 & -.01 & .02 & -.01 & .403 \\
\hline $\begin{array}{l}\text { Within-group strategic consensus in } \\
\text { dyad }\end{array}$ & .98 & .11 & .43 & .001 & .97 & .10 & .42 & .001 & 1.01 & .10 & .44 & .001 \\
\hline \multicolumn{13}{|l|}{ Predictor variables } \\
\hline Organizational identification in dyad & & & & & .03 & .06 & .03 & .306 & .03 & .06 & .03 & .293 \\
\hline Group identification in dyad & & & & & -.25 & .06 & -.24 & .001 & -.23 & .06 & -.22 & .001 \\
\hline \multicolumn{13}{|l|}{ Level 1 interaction } \\
\hline $\begin{array}{l}\text { Group Identification } \times \text { Organizational } \\
\text { Identification in Dyad }\end{array}$ & & & & & & & & & -.79 & .18 & -.15 & .001 \\
\hline
\end{tabular}

Note. Entries are derived by the MRQAP double Dekker semipartialing method at 2,000 permutations. MRQAP = multiple regression quadratic assignment procedure.

elaboration $(r=.13, p=.000)$, and strategic involvement $(r=.10, p=.001)$. These correlations suggest that interdependent groups are more likely to communicate, form a structural link, be at the same level, elaborate more with other groups, and be more strategically involved than noninterdependent groups. Finally, we note that the correlations indicate that interdependent dyads do not significantly differ in their level of within-group strategic consensus $(r=.00, n s)$ but do have slightly more intergroup strategic consensus than noninterdependent dyads $(r=.07, p=.003)$.

Table 2 shows the results of MRQAP analyses for the 451 intergroup dyads, where all the continuous independent variables were centered to increase the interpretability. The first step includes the control variables and indicates that dyads that have more within-group consensus $(\beta=0.43, p=.001)$ and communicate more $(\beta=0.12, p=.001)$ have higher intergroup strategic consensus, whereas a structural link between groups $(\beta=-0.10, p=.005)$, groups in a dyad being at the same hierarchical level $(\beta=-0.07, p=.008)$, and strategic involvement $(\beta=-0.10, p=.006)$ in a dyad lower intergroup strategic consensus.

The second step includes all main variables. This step did not support Hypothesis 1, that higher organizational identification in a dyad is associated with higher intergroup strategic consensus $(\beta=0.03, n s)$. The results in Step 2 provided support for Hypothesis 2, which indicates that higher group identification in a dyad is associated with lower intergroup strategic consensus $(\beta=-0.24, p=.001)$.

In Step 3, we added the interaction between organizational identification and group identification. In line with our Hypothesis 3, the coefficient for the interaction was negative and 
Figure 2

The Effect of Organizational Identification on Intergroup Strategic Consensus Contingent on Group Identification

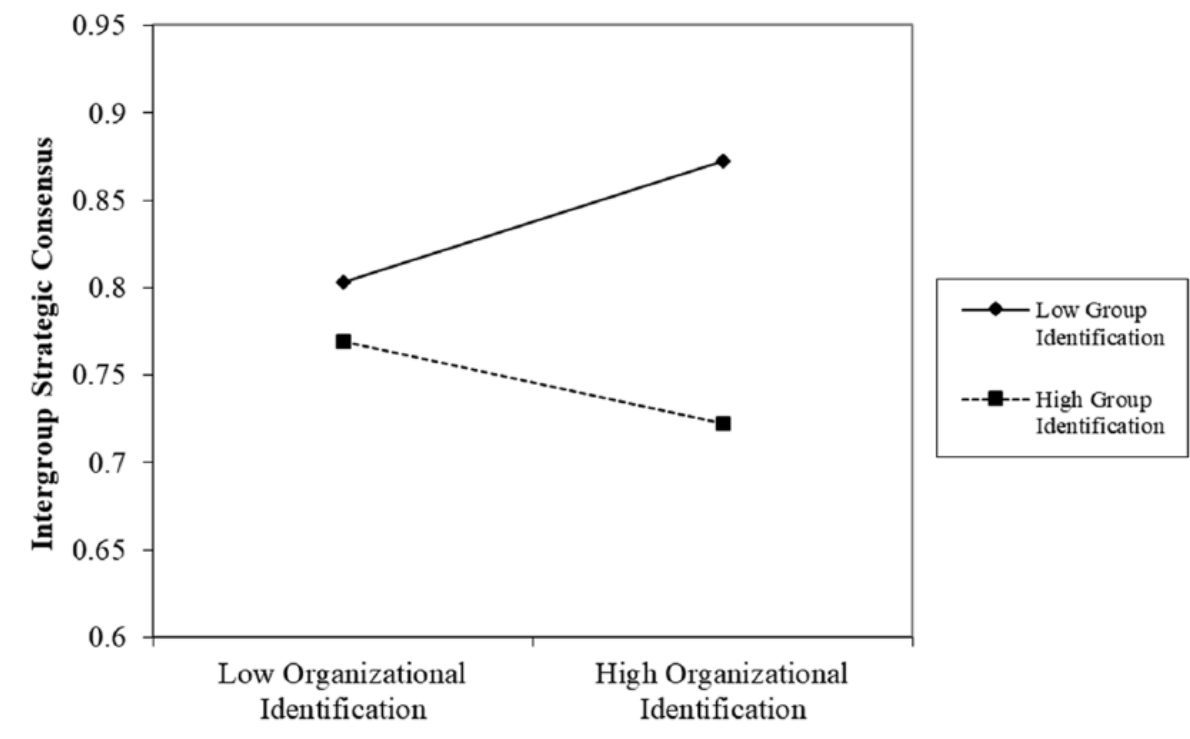

statistically significant $(\beta=-0.15, p=.001)$. To explore the nature of the interaction effect, we plotted the interaction in line with recommendations by Aiken and West (1991; see Figure 2). As shown in this figure, organizational identification is positively related to intergroup consensus only for low levels of group identification. For robustness, we also conducted our analyses excluding the control variables and find that the results of these analyses are qualitatively similar to the results presented above (organizational identification, $\beta=0.09, p=.057$; group identification, $\beta=-0.28, p=.001$; interaction, $\beta=-0.11, p=.005$ ).

\section{Additional Analysis}

Our work builds on the premise that intergroup strategic consensus is beneficial for organizations when the TMT has formulated and agreed on a strategy and seeks to implement this through organizationwide effort. To be beneficial, intergroup strategic consensus should thus be aligned with the strategic direction set forth by the TMT. Although it is possible that intergroup dyads have high intergroup strategic consensus that is not in alignment with the TMT, in practice it is more likely to be in alignment with the TMT. Indeed, several strategy scholars have argued and demonstrated that "the strategy process involves a consensus building process ... during which organizational members develop a general level of agreement on the fundamental priorities of the organization" (Markóczy, 2001: 1013; see also Balogun \& Johnson, 2005; Wooldridge \& Floyd, 1989).

To establish whether this was indeed the case in our organization, we examine the correlation between dyad's strategic alignment with the TMT and their intergroup strategic consensus. 
For each team, alignment with the TMT was calculated by looking at $r$ (TMT, A) (Tarakci et al., 2014). Thereafter it was translated into to the relational level by averaging the alignment scores of the two teams $(M=0.63, S D=0.15)$. The correlation between intergroup strategic consensus and dyad's average strategic alignment with the TMT is strong and positive $(r=.79, p=.001)$. This indicates that intergroup strategic consensus and the dyad's strategic alignment with the TMT are related yet distinct constructs. Moreover, these findings suggests that when intergroup dyads have strong intergroup strategic consensus, this consensus tends to be in alignment with the strategic direction set forth by the TMT. ${ }^{4}$

\section{Replication Study}

Our replication study was conducted in a midsized information and communications technology (ICT) service company from Western Europe that specializes in the design, development, and implementation of sector-specific ICT systems. Like the organization in the main study, this organization was in the strategy implementation phase, after top management had formulated this organization's seven strategic priorities: efficiency, quality, tooling, internal cooperation, external cooperation, vertical knowledge, and horizontal knowledge. Like in the main study, the organization consisted of different, highly task-interdependent work groups spread over various locations, with different areas of expertise that must be integrated to ensure successful ICT system implementations.

The survey was sent to all 41 work groups in the organization and the TMT (394 respondents in total). The response rate was $81 \%$. We separated the TMT from the sample and discarded two groups with less than 50\% response rate and two groups with only two respondents. The discarded teams did not differ from the teams in the sample with respect to any of the study's independent variables (largest $t$ value was $1.26, p=.217$ ). Our final sample consisted of 37 teams, ranging in size from three to 19 members, with an average of 8.24 persons per group and a mean within-group response rate of $86.18 \%$. The mean age of the participants was $40.3(S D=8.0) ; 87.2 \%$ were male. Participants had on average 5.55 years $(S D=4.1)$ of work experience; $84.26 \%$ had a bachelor's degree or higher.

For these 37 work groups, 191 intergroup dyads were identified, that is, work groups were part of five to six intergroup dyads. We study the role of group and organizational identification on intergroup strategic consensus within these 191 intergroup dyads. We adopted the same measures as in the main study. For the strategic consensus and alignment measures, we used the seven firm-specific strategic priorities formulated by the TMT. The $r_{w g}$ values provided support for aggregation, and we ascertained the discriminant and convergent validity of the constructs through CFA. The descriptive statistics and correlations are presented in Table 3 .

Table 4 shows the results of MRQAP analyses for the 191 intergroup dyads, where all the continuous independent variables were centered to increase the interpretability. The first step includes the control variables and indicates that dyads that have more withingroup consensus $(\beta=0.27, p=.001)$ or communicate more $(\beta=0.09, p=.046)$ have higher intergroup strategic consensus, whereas dyads that have groups at the same hierarchical level $(\beta=-0.09, p=.038)$ and have strategic involvement $(\beta=-0.11, p=.072)$ have lower intergroup strategic consensus. The second step includes all main variables. This step confirmed Hypothesis 1 , such that higher organizational identification in a dyad is associated with higher intergroup strategic consensus $(\beta=.23, p=.003)$. The results in 


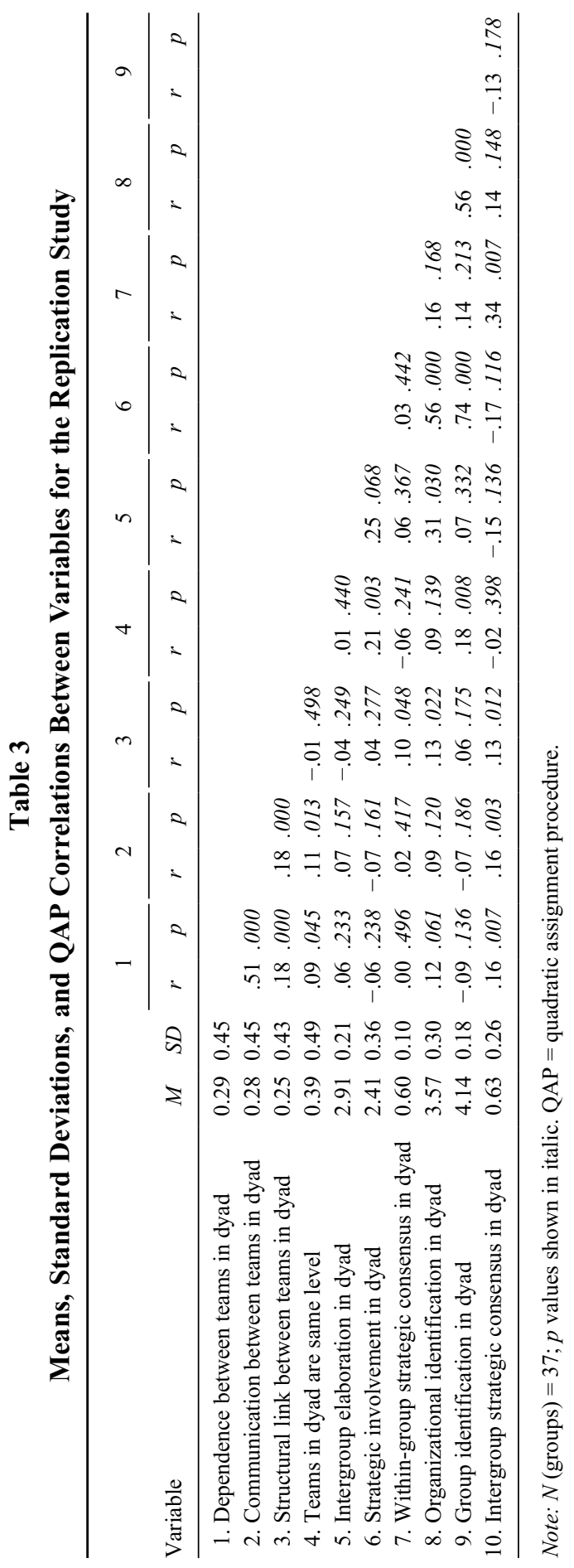


Table 4

The Effect of Organizational and Group Identification on Intergroup Strategic Consensus, MRQAP Regression Results for the Replication Study

\begin{tabular}{|c|c|c|c|c|c|c|c|c|c|c|c|c|}
\hline \multirow[b]{2}{*}{ Variable } & \multicolumn{4}{|c|}{ Step 1} & \multicolumn{4}{|c|}{ Step 2} & \multicolumn{4}{|c|}{ Step 3} \\
\hline & $b$ & $S E$ & $\beta$ & $p$ & $b$ & $S E$ & $\beta$ & $p$ & $b$ & $S E$ & $\beta$ & $p$ \\
\hline Intercept & .68 & .00 & & .001 & .67 & .00 & & .000 & .68 & .00 & & .000 \\
\hline \multicolumn{13}{|l|}{ Controls } \\
\hline $\begin{array}{l}\text { Communication between } \\
\text { teams in dyad }\end{array}$ & .04 & .01 & .09 & .046 & .04 & .02 & .11 & .017 & .04 & .02 & .11 & .021 \\
\hline $\begin{array}{l}\text { Structural link between teams } \\
\text { in dyad }\end{array}$ & .02 & .02 & .06 & .180 & .01 & .02 & .03 & .348 & .03 & .02 & .07 & .122 \\
\hline Teams in dyad are same level & -.04 & .01 & -.09 & .038 & -.02 & .02 & -.05 & .173 & -.02 & .02 & -.05 & .177 \\
\hline Intergroup elaboration in dyad & -.06 & .36 & -.06 & .219 & -.20 & .08 & -.19 & .006 & -.20 & .08 & -.20 & .006 \\
\hline Strategic involvement in dyad & -.06 & .02 & -.11 & .072 & .03 & .07 & .04 & .376 & .06 & .07 & .10 & .186 \\
\hline $\begin{array}{l}\text { Within-group strategic } \\
\text { consensus in dyad }\end{array}$ & .55 & .11 & .27 & .001 & .66 & .15 & .32 & .001 & .72 & .15 & .35 & .001 \\
\hline \multicolumn{13}{|l|}{ Predictor variables } \\
\hline $\begin{array}{l}\text { Organizational identification } \\
\text { in dyad }\end{array}$ & & & & & .15 & .06 & .23 & .003 & .13 & .06 & .19 & .008 \\
\hline Group identification in dyad & & & & & -.41 & .06 & -.36 & .001 & -.37 & .13 & -.33 & .001 \\
\hline \multicolumn{13}{|l|}{ Level 1 interaction } \\
\hline $\begin{array}{l}\text { Group Identification } \times \\
\text { Organizational Identification } \\
\text { in Dyad }\end{array}$ & & & & & & & & & -.67 & .23 & -.18 & .003 \\
\hline
\end{tabular}

Note: Entries are derived by the MRQAP double Dekker semipartialing method at 2,000 permutations. MRQAP = multiple regression quadratic assignment procedure.

Step 2 also confirmed Hypothesis 2, which indicates that higher group identification in a dyad is associated with lower intergroup strategic consensus $(\beta=-0.36, p=.001)$. Finally, in Step 3, we added the interaction between organizational identification and group identification. In line with our Hypothesis 3, the coefficient for the interaction was negative and significant $(\beta=-0.18, p=.003)$. To explore the nature of the interaction effect, we plotted the interaction (see Figure 3 ). As shown in this figure, organizational identification is positively related to intergroup consensus only for low levels of group identification. For robustness, we also conducted our analyses excluding the control variables and find that the results of these analyses are qualitatively similar to the results presented above (organizational identification, $\beta=0.17, p=.017$; group identification, $\beta=-.18$, $p=.023$; interaction, $\beta=-0.09, p=.089$ ).

Finally, we calculated the correlation between intergroup strategic consensus and dyad's average strategic alignment with the TMT. The correlation between intergroup strategic consensus and strategic alignment with the TMT is strong and positive $(r=.53$, $p=.000$ ), which suggests that when intergroup dyads have strong intergroup strategic consensus, this consensus tends to be in alignment with the strategic direction set forth by the TMT. 
Figure 3

The Effect of Organizational Identification on Intergroup Strategic Consensus Contingent on Group Identification in the Replication Study

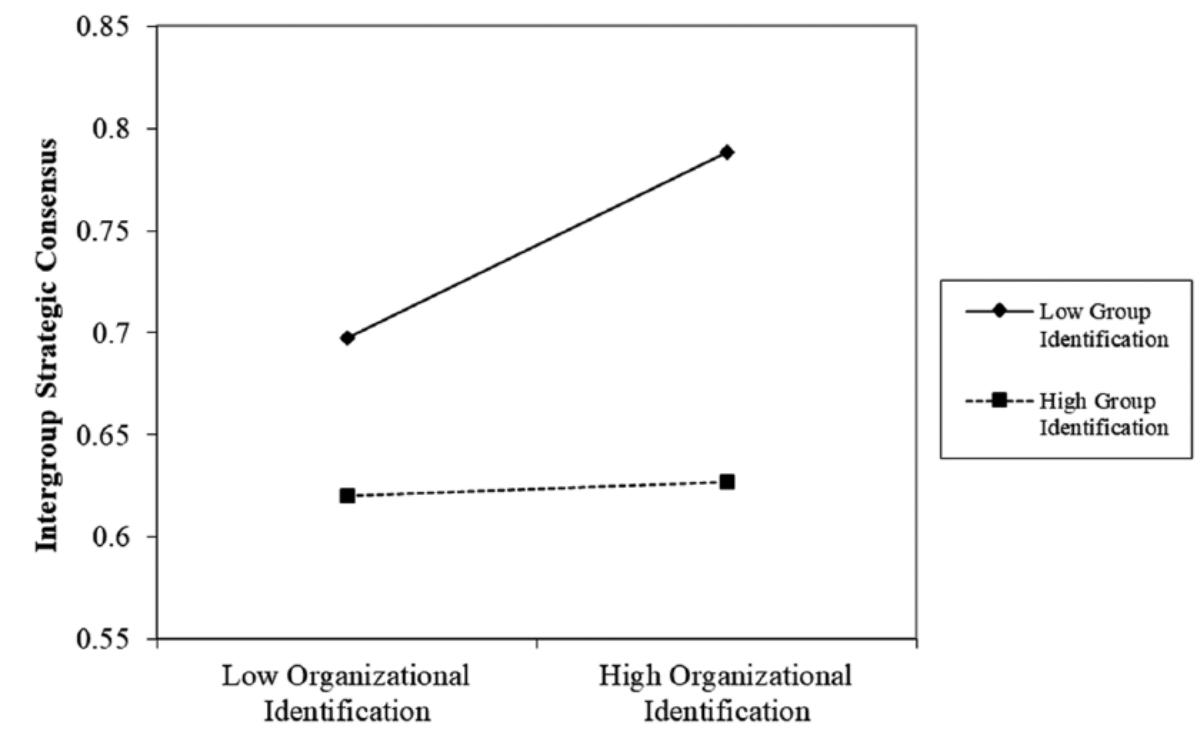

\section{Discussion}

The challenge many organizations face in dealing with between-team issues that hinder strategy implementation is aligning their teams' understandings of the organization's strategy (e.g., Balogun \& Johnson, 2005; Floyd \& Wooldridge, 1992a; Raes et al., 2011). We build on the social identity literature to develop an understanding of the influence of organizational and group identification on such shared understanding of strategy between interdependent teams throughout the organization: intergroup strategic consensus. In two studies, we found partial support for the prediction that organizational identification is positively related to intergroup strategic consensus, and full support for the prediction that group identification is negatively related to intergroup consensus. We also found in both studies that organizational identification and group identification interact in predicting intergroup strategic consensus, such that organizational identification is positively related to intergroup consensus only for lower levels of group identification. Offering a social identity perspective on strategic intergroup consensus, we provide an understanding of the phenomenon of intergroup strategic consensus, extend the conversation in strategy process research from within-team to betweenteam consensus, and challenge the assumption that higher identification is always desirable.

\section{Theoretical Implications}

Our first theoretical contribution is to strategy process research, to which we offer a social identity perspective on intergroup strategic consensus. Introducing this perspective to 
develop an understanding of intergroup strategic consensus answers calls to strengthen the psychological grounding and practical usefulness of strategy theory by grounding strategic management in realistic assumptions about human cognition and social interaction, along the lines of behavioral strategy (Hutzschenreuter \& Kleindienst, 2006; Powell et al., 2011). Research on social identity and the psychology of organizational identifications allowed us to bridge the gap between team cognition and organizational strategy. The social identity perspective we propose addresses the core of the challenge of establishing intergroup consensus, as this perspective is well suited for understanding intergroup relations. Indeed, outside of the strategy literature, the social identity perspective has been established as the primary framework for understanding intergroup psychological barriers that may hinder interdependent teams' coordination activities, such as intergroup bias, intergroup competition, and silo mentality (Hogg et al., 2012).

Second, as we develop an understanding of intergroup strategic consensus, we shift the conversation in strategy process research, especially strategic consensus research, from team outcomes to between-team interdependencies and intergroup-level outcomes. We do so in line with the increasing recognition that teams do not operate in isolation to implement strategy (Hutzschenreuter \& Kleindienst, 2006; Noda \& Bower, 1996; Tsai, 2002). Thereby, we respond to the repeated calls in strategy process research to focus on the challenges associated with aligning strategic efforts throughout the organization (Floyd \& Wooldridge, 1992a; Raes et al., 2011) and calls in the strategic consensus literature to investigate strategic consensus between teams (Kellermanns et al., 2005, 2011; Tarakci et al., 2014). Efforts following up on those calls have thus far been limited. In fact, only recently Tarakci and colleagues (2014) proposed an approach to measure consensus between teams. In that sense, our work contributes to the strategy process literature through the use of this approach by Tarakci et al. to measure intergroup strategic consensus and the use of MRQAP (Dekker et al., 2007) to allow hypothesis testing at the intergroup level of analysis. We show that there is variation in intergroup strategic consensus that is independent of variation in within-group strategic consensus or alignment with the TMT (both group-level variables). This underscores that intergroup strategic consensus is worthy of study as an outcome in its own right, as has been argued conceptually (e.g., Kellermanns et al., 2005).

Our focus on intergroup strategic consensus also led us to do something that is worth highlighting here - study strategic consensus beyond the top management. Strategic consensus research has had a strong emphasis on top management (West \& Schwenk, 1996; Wooldridge \& Floyd, 1989). There is increasing recognition that the strategy process unfolds well beyond the TMT and that the coordination and cooperation that strategic consensus would serve is critically contingent on the understanding and actions of teams at all levels in the organization (Floyd \& Wooldridge, 1992b; Jarzabkowski \& Spee, 2009; Raes et al., 2011). Acknowledging the importance of intergroup strategic consensus, therefore, is integral to a better understanding of the complexities of the strategy process. As a concept, intergroup strategic consensus may explain why prior strategic consensus studies could not consistently find a relationship between within-team consensus and organizational performance, because for that performance, different teams need each other and thus need betweenteam strategic consensus. Our study's focus on intergroup strategic consensus at all levels may be an important step toward a better understanding of the consensus-performance relationship. 
There has been a clear tendency in management research and practice to view identification as a positive influence (Erickson, 2010; Gratton \& Erickson, 2007; Reitzig \& Sorenson, 2013). This is not surprising given the large body of work highlighting the positive influence of group identification on group dynamics. Our study challenges this positive view and specifically the dual-identity perspective. On the basis of the state of the science in intergroup relations (Hogg et al., 2012), we argue that strong dual identity does not increase intergroup strategic consensus. Rather, for intergroup strategic consensus, group identification is a negative influence - and a negative influence that cannot be countered by organizational identification (cf. the notion of in-group projection; Hogg et al., 2012; Mummendey \& Wenzel, 1999). Our theorizing and results thereby challenge the general belief that organizations should always aim for their members to identify strongly with both their group and the organization.

Furthermore, our social identity perspective of intergroup strategic consensus provides a meaningful extension of the work on social identity in the management literature that has a strong focus on intragroup effects of social identification with much less attention to intergroup effects (Hogg et al., 2012; van Knippenberg, 2003). In fact, despite the burgeoning research on social identification in management, very few studies have so far considered intergroup outcomes in organizations (Hogg et al., 2012), let alone intergroup outcomes in the strategy process. The present studies thus constitute an important step forward in the development of the social identity perspective on intergroup outcomes by establishing the interactive effect of group and organizational identification. Moreover, we shift the emphasis from individual-level evaluations to intergroup-level cognition that is substantially more proximal to the intergroup behavioral processes organizations would seek to stimulate. The current analyses thus may substantially broaden the basis for the study of intergroup-level phenomena in organizations.

\section{Limitations and Future Research}

The current work is not without limitations. First, our main study and replication study are cross-sectional. Our studies and their support for our hypotheses offer more evidence and confidence in the validity of the social identity perspective, as they demonstrate that our findings generalize to another setting (company). Yet, we are careful to avoid conclusions about causality, even when our conceptual analyses would imply causality with identifications influencing intergroup strategic consensus. Future research that addresses these issues in a field experiment would be very valuable in this respect.

Second, in both studies, all data were drawn from a single survey, and in this respect it is important to note that we followed the "procedural remedy" recommendations on dealing with common method variance in the design of our study (Podsakoff et al., 2003, 2012; Spector, 2006). Common method variance may be an issue for survey research because it can inflate percept-percept relationships for main effects. Our study, however, examines intergroup strategic consensus, which is not a perception but a computational measure (cf. Meier \& O'Toole, 2013; Podsakoff et al., 2003), and core to our analysis is an interaction effect, which cannot be explained by common method variance-interactions actually become more difficult to detect with common method effects (Evans, 1985; McClelland \& Judd, 1993). As such, we believe a concern with common method variance applies less here than in many other cases. 
Third, we should note that our focus on intergroup strategic consensus builds on the proposition that such strategic consensus is important in the strategy implementation process once the TMT has formulated a strategy and seeks its implementation. There are boundaries to the benefits of intergroup strategic consensus, however. In the hypothetical extreme scenario, where teams have perfect intergroup strategic consensus that is in complete misalignment with the TMT, this will not be helpful to the strategy implementation. Although the significant and positive correlation between intergroup strategic consensus and dyad's alignment with the TMT in both of our studies suggest that such an extreme scenario is not typical in practice, scholars should be careful to assume strategic consensus is always in the service of strategy implementation. Obviously, the present study can speak only to the determinants of intergroup consensus and not to its anticipated consequences. Given the promising results of this study, extending the current approach to investigating the effect of intergroup strategic consensus on strategy implementation and organizational performance would be an obvious next step.

Finally, in both studies, we controlled for the role of teams being at the same hierarchical level, which was positively related with intergroup strategic consensus in our main study but not in the replication. This suggests that hierarchical dynamics may influence intergroup strategic consensus under certain circumstances. This offers a valuable avenue for future research. Moreover, by identifying intergroup dyads as the unit of analysis for the study of intergroup strategic consensus, this research examined networks of interdependent ties within an organization, in which different teams have to collaborate and coordinate with each other (e.g., Tsai, 2002). We believe our work underscores the importance and usefulness of network theory and provides building blocks for the development of our understanding of intergroup networks.

\section{Managerial Implications}

Given the emphasis organizations normally place on teams by, for example, engaging employees in team-building activities or setting team goals, it is important to recognize that such a focus on teams may impact relationships between teams. Our findings from two different organizations show that group identification lowers teams' shared understanding of the strategy with other teams upon which they depend. Identification with the organization has a positive effect on strategic consensus between teams and thus is more helpful to organizations, but it cannot compensate for the harmful effect of strong group identification. To shift teams' attention away from focusing too much on the team, organizations should set cooperative goals (Wrzesniewski \& Dutton, 2001) and explain how team goals tie in with the overall strategy of the organization (Kramer, 1991; van Knippenberg, 2003). This may not only enable teams to accommodate the needs of other teams more effectively but may also make them prouder of what they contribute to the organization (Wrzesniewski \& Dutton, 2001).

\section{Conclusion}

Adopting a social identity perspective, we clarify how social identifications in interdependent teams can influence their intergroup strategic consensus. Our results demonstrate that group identification, which is often associated with positive team outcomes, is 
detrimental to intergroup strategic consensus. In contrast, organizational identification can foster intergroup consensus but cannot compensate for the negative influence of group identification. Our approach and results not only provide support for the value of the social identity perspective for development of a more comprehensive understanding of strategic consensus. They also underscore the need to investigate what drives the behaviors and cognition in all teams that put strategy into practice and do so together with other teams. We believe this understanding of intergroup relations is crucial and hope many will follow us on the way toward more understanding of the multilevel complexities of the strategy process in organizational practice.

\section{Notes}

1. The data reported in this manuscript have been collected as part of a larger data collection. Findings from the data collection have been reported in separate manuscripts. Tarakci, Ates, Porck, van Knippenberg, Groenen, and de Haas (2014) used a subsample of nine teams and the top management team (TMT) as an illustrative case to demonstrate strategic consensus mapping. Ates, Tarakci, Porck, van Knippenberg, and Groenen (2018) use the within-group strategic consensus data of a subsample of 88 teams to test the mechanism through which middle and lower-level managers' visionary leadership affects their teams' strategic commitment.

2. Strategic consensus mapping (SCM; see Tarakci et al., 2014) consists of a set of methodological procedures, readily available online at https:/mtarakci.shinyapps.io/consensus/. We used SCM on data that quantify how respondents rank ordered the strategic priorities of their organization. The online tool automatically follows SCM's methodological procedures, described below, to derive two measures: the $\alpha$ measure, which ranges from 0 to 1 , to capture the degree of within-group strategic consensus and the $r(A, B)$ measure, which ranges from -1 to 1 , to capture the degree of between-group strategic consensus.

Thus, first, a principal component analysis (PCA) is conducted on the transposed data matrix (respondents in the columns and strategy items in the rows). This provides a two-dimensional map that jointly plots the strategy items in relation to all group members' individual rankings of these items. In this map, strategy items are represented as points and respondents as vectors. The spread of all vectors demonstrates the degree of within-group strategic consensus. Moreover, the correlation of the scores of the strategy items on the average component loading of the respondents per group over the first two principal components of the PCA can be interpreted as the prototypical group member, who represents the overall group opinion the best.

Second, to calculate the $\alpha$ measure, the degree of within-group strategic consensus, the PCA component loadings of the group members are used. The $\alpha$ measure, is defined as follows:

$$
\alpha=\sqrt{\sum_{s-1}^{2}\left(m^{-1} \sum_{j} a_{j s}\right)^{2}} \text { where } \alpha_{j s} \text { is the } s \text { th component loading for respondent } j(j=1, \ldots, n) \text {. If all members }
$$

of the group share exactly the same view of the strategy items, the $\alpha$ measure will be close to 1 ; when there is very low strategic consensus, the $\alpha$ measure will be close to 0 .

Last, to calculate the $r$ measure, the degree of between-group consensus, the within-group PCA object scores of the strategy items are used. The measure operationalizes the degree of intergroup strategic consensus, $r(A, B)$, as the correlation of the scores of the strategy items on the average component loading (i.e., prototypical team member for a group) of the respondents per group over the first two principal components of the PCA for each of the two work groups A and B. Accordingly, an $r(\mathrm{~A}, \mathrm{~B})$ of 1 indicates full consensus between the work groups, an $r(\mathrm{~A}, \mathrm{~B}) \approx$ 0 represents low consensus between the two work groups, and an $r(\mathrm{~A}, \mathrm{~B}) \approx-1$ reveals two opposite notions of the strategic priorities in the two work groups.

3. We also ran a post hoc analysis of our models with dyad's maximum group identification and minimum organizational identification instead of the mean scores of identification. These results are qualitatively similar; the interaction is significant and in the expected direction.

4. We also ran a post hoc analysis of our models with dyad's strategic alignment with the TMT as a control. These results are qualitatively similar; the interaction results hold and show the same pattern as the results without alignment with the TMT as control. 


\section{References}

Aiken, L. S., \& West, S. G. 1991. Multiple regression: Testing and interpreting interactions. Newbury Park, CA: Sage.

Ashforth, B. E., Harrison, S. H., \& Corley, K. G. 2008. Identification in organizations: An examination of four fundamental questions. Journal of Management, 34: 325-374.

Ashforth, B. E., \& Mael, F. 1989. Social identity theory and the organization. Academy of Management Review, 14: $20-39$.

Ates, N. Y., Tarakci, M., Porck, J. P., van Knippenberg, D., \& Groenen, P. J. F. 2018. The dark side of visionary leadership in strategy implementation. Unpublished manuscript.

Balogun, J. 2006. Managing change: Steering a course between intended strategies and unanticipated outcomes. Long Range Planning, 39: 29-49.

Balogun, J., \& Johnson, G. 2005. From intended strategies to unintended outcomes: The impact of change recipient sensemaking. Organization Studies, 26: 1573-1601.

Bettis, R. A., Helfat, C. E., \& Shaver, J. M. 2016. The necessity, logic, and forms of replication. Strategic Management Journal, 37: 2193-2203.

Borgatti, S. P., Everett, M. G., \& Freeman, L. C. 2002. Ucinet for Windows: Software for social network analysis. Harvard, MA: Analytic Technologies.

Boyer, K. K., \& Pagell, M. 2000. Measurement issues in empirical research: Improving measures of operations strategy and advanced manufacturing technology. Journal of Operations Management, 18: 361-374.

Brewer, M. B. 1997. The social psychology of intergroup relations: Can research inform practice? Journal of Social Issues, 53: 197-211.

Chen, G., Mathieu, J. E., \& Bliese, P. D. 2004. A framework for conducting multi-level construct validation. In F. J. Yammarino \& F. Dansereau (Eds.), Research in multilevel issues: Multilevel issues in organizational behavior and processes: 273-303. Oxford, UK: Elsevier.

Crittenden, V. L., Gardiner, L. R., \& Stam, A. 1993. Reducing conflict between marketing and manufacturing. Industrial Marketing Management, 22: 299-309.

Cronin, M. A., \& Weingart, L. R. 2007. Representational gaps, information processing, and conflict in functionally diverse teams. Academy of Management Review, 32: 761-773.

De Cremer, D., van Knippenberg, D., van Dijk, E., \& van Leeuwen, E. 2008. Cooperating if one's goals are collective-based: Social identification effects in social dilemmas as a function of goal transformation. Journal of Applied Social Psychology, 38: 1562-1579.

Dekker, D., Krackhardt, D., \& Snijders, T. A. B. 2007. Sensitivity of MRQAP tests to collinearity and autocorrelation conditions. Psychometrika, 72: 563-581.

Dooley, R. S., \& Fryxell, G. E. 1999. Attaining decision quality and commitment from dissent: The moderating effects of loyalty and competence in strategic decision-making teams. Academy of Management Journal, 42: 389-402.

Dovidio, J. F., \& Gaertner, S. L. 2010. Intergroup bias. In S. T. Fiske, D. Gilbert, \& G. Lindzey (Eds.), Handbook of social psychology, vol. 2, 5th ed.: 1084-1121. New York: Wiley.

Erickson, T. J. 2010. The leaders we need now. Harvard Business Review, 88: 63-66.

Evans, M. G. 1985. A Monte Carlo study of the effects of correlated method variance in moderated multiple regression analysis. Organizational Behavior and Human Decision Processes, 36: 305-323.

Floyd, S. W., \& Wooldridge, B. 1992a. Managing strategic consensus: The foundation of effective implementation. The Executive, 6: 27-39.

Floyd, S. W., \& Wooldridge, B. 1992b. Middle management involvement in strategy and its association with strategic type: A research note. Strategic Management Journal, 13: 153-167.

Gaertner, S. L., Dovidio, J. F., \& Bachman, B. A. 1996. Revisiting the contact hypothesis: The induction of a common ingroup identity. International Journal of Intercultural Relations, 20: 271-290.

Gaertner, S. L., Dovidio, J. F., Rust, M. C., Nier, J. A., Banker, B. S., Ward, C. M., Mottola, G. R., \& Houlette, M. 1999. Reducing intergroup bias: Elements of intergroup cooperation. Journal of Personality and Social Psychology, 76: 388-402.

Gagnon, M. A., Jansen, K. J., \& Michael, J. H. 2008. Employee alignment with strategic change: A study of strategy-supportive behavior among blue-collar employees. Journal of Managerial Issues, 20: 425-443.

González-Benito, J., Aguinis, H., Boyd, B. K., \& Suárez-González, I. 2012. Coming to consensus on strategic consensus: A mediated moderation model of consensus and performance. Journal of Management, 38: 1685-1714. 
Gratton, L., \& Erickson, T. J. 2007. Eight ways to build collaborative teams. Harvard Business Review, 85: 100-109. Haslam, S. A. 2004. Psychology in organizations: The social identity approach (2nd ed.). London: Sage.

Hogg, M. A., \& Terry, D. J. 2000. Social identity and self-categorization processes in organizational contexts. Academy of Management Review, 25: 121-140.

Hogg, M. A., van Knippenberg, D., \& Rast, D. E. 2012. Intergroup leadership in organizations: Leading across group and organizational boundaries. Academy of Management Review, 37: 232-255.

Hornsey, M. J., \& Hogg, M. A. 2000. Assimilation and diversity: An integrative model of subgroup relations. Personality and Social Psychology Review, 4: 143-156.

Hutzschenreuter, T., \& Kleindienst, I. 2006. Strategy-process research: What have we learned and what is still to be explored. Journal of Management, 32: 673-720.

Ibarra, H. 1993. Network centrality, power, and innovation involvement: Determinants of technical and administrative roles. Academy of Management Journal, 38: 471-501.

Jarzabkowski, P., \& Spee, P. A. 2009. Strategy-as-practice: A review and future directions for the field. International Journal of Management Reviews, 11: 69-95.

Kellermanns, F. W., Walter, J., Floyd, S. W., Lechner, C., \& Shaw, J. C. 2011. To agree or not to agree? A metaanalytical review of strategic consensus and organizational performance. Journal of Business Research, 64: 126-133.

Kellermanns, F. W., Walter, J., Lechner, C., \& Floyd, S. W. 2005. The lack of consensus about strategic consensus: Advancing theory and research. Journal of Management, 31: 719-737.

Ketokivi, M., \& Castañer, X. 2004. Strategic planning as an integrative device. Administrative Science Quarterly, 49: $337-365$.

Kilduff, M., \& Krackhardt, D. 1994. Bringing the individual back in: A structural analysis of the internal market for reputation in organizations. Academy of Management Journal, 37: 87-108.

Klein, K. J., \& Kozlowski, S. W. J. 2000. From micro to meso: Critical steps in conceptualizing and conducting multilevel research. Organizational Research Methods, 3: 211-236.

Krackhardt, D. 1988. Predicting with networks: Nonparametric multiple regression analysis of dyadic data. Social Networks, 10: 359-381.

Kramer, R. M. 1991. Intergroup relations and organizational dilemmas: The role of categorization processes. Research in Organizational Behavior, 13: 191-228.

Lee, E., \& Puranam, P. 2016. The implementation imperative: Why one should implement even imperfect strategies perfectly. Strategic Management Journal, 37: 1529-1546.

Lingle, J. H., \& Schiemann, W. A. 1996. From balanced scorecard to strategic gauges: Is measurement worth it? Management Review, 85: 56-61.

Mael, F., \& Ashforth, B. E. 1992. Alumni and their alma mater: A partial test of the reformulated model of organizational identification. Journal of Organizational Behavior, 13: 103-123.

Markóczy, L. 2001. Consensus formation during strategic change. Strategic Management Journal, 22: 1013-1031.

McClelland, G. H., \& Judd, C. M. 1993. Statistical difficulties of detecting interactions and moderator effects. Psychological Bulletin, 114: 376-390.

Meier, K. J., \& O’Toole, L. J. 2013. Subjective organizational performance and measurement error: Common source bias and spurious relationships. Journal of Public Administration Research and Theory, 23: 429-456.

Mummendey, A., \& Wenzel, M. 1999. Social discrimination and tolerance in intergroup relations: Reactions to intergroup difference. Personality and Social Psychology Review, 3: 158-174.

Noda, T., \& Bower, J. L. 1996. Strategy making as iterated processes of resource allocation. Strategic Management Journal, 17(S1): 159-192.

Pettigrew, T. F. 1998. Intergroup contact theory. Annual Review of Psychology, 49: 65-85.

Pettigrew, T. F., \& Tropp, L. R. 2006. A meta-analytic test of intergroup contact theory. Journal of Personality and Social Psychology, 90: 751-783.

Podsakoff, P. M., MacKenzie, S. B., Lee, J., \& Podsakoff, N. P. 2003. Common method biases in behavioral research: A critical review of the literature and recommended remedies. Journal of Applied Psychology, 88: 879-903.

Podsakoff, P. M., MacKenzie, S. B., \& Podsakoff, N. P. 2012. Sources of method bias in social science research and recommendations on how to control it. Annual Review of Psychology, 63: 539-569.

Powell, T. C., Lovallo, D., \& Fox, C. R. 2011. Behavioral strategy. Strategic Management Journal, 32: 1369-1386.

Raes, A. M. L., Heijltjes, M. G., Glunk, U., \& Roe, R. A. 2011. The interface of the top management team and middle managers: A process model. Academy of Management Review, 36: 102-126.

Ramarajan, L. 2014. Past, present and future research on multiple identities: Toward an intrapersonal network approach. Academy of Management Annals, 8: 589-659. 
Raver, J. L., \& van Knippenberg, D. 2007. Openness to diversity and the informational benefits of gender diversity. Paper presented at the 22nd annual conference of the Society for Industrial and Organizational Psychology, New York.

Reitzig, M., \& Sorenson, O. 2013. Biases in the selection stage of bottom-up strategy formulation. Strategic Management Journal, 34: 782-799.

Richter, A. W., West, M. A., van Dick, R., \& Dawson, J. F. 2006. Boundary spanners' identification, intergroup contact, and effective intergroup relations. Academy of Management Journal, 49: 1252-1269.

Riketta, M., \& van Dick, R. 2005. Foci of attachment in organizations: A meta-analytic comparison of the strength and correlates of workgroup versus organizational identification and commitment. Journal of Vocational Behavior, 67: 490-510.

Samba, C., Van Knippenberg, D., \& Miller, C. C. 2018. The impact of strategic dissent on organizational outcomes: A meta-analytic integration. Strategic Management Journal, 39: 379-402

Spector, P. E. 2006. Method variance in organizational research truth or urban legend? Organizational Research Methods, 9: 221-232.

St John, C. H., \& Rue, L. W. 1991. Research notes and communications co-ordinating mechanisms, consensus between marketing and manufacturing groups, and marketplace performance. Strategic Management Journal, 12: 549-555.

Tajfel, H. T., \& Turner, J. C. 1979. An integrative theory of intergroup conflict. In W. G. Austin \& S. Worchel (Eds.), The social psychology of intergroup relations: 33-47. Monterey, CA: Brooks/Cole.

Tajfel, H. T., \& Turner, J. C. 1986. The social identity theory of intergroup behavior. In S. Worchel \& W. G. Austin (Eds.), The psychology of intergroup relations: 7-24. Chicago: Nelson-Hall.

Tarakci, M., Ates, N. Y., Porck, J. P., van Knippenberg, D., Groenen, P. J. F., \& de Haas, M. 2014. Strategic consensus mapping: A new method for testing and visualizing strategic consensus within and between teams. Strategic Management Journal, 35: 1053-1069.

Tsai, W. 2002. Social structure of "coopetition" within a multiunit organization: Coordination, competition, and intraorganizational knowledge sharing. Organization Science, 13: 179-190.

Van Dick, R., Grojean, M. W., Christ, O., \& Wieseke, J. 2006. Identity and the extra mile: Relationships between organizational identification and organizational citizenship behaviour. British Journal of Management, 17: 283-301.

van Dick, R., van Knippenberg, D., Kerschreiter, R., Hertel, G., \& Wieseke, J. 2008. Interactive effects of work group and organizational identification on job satisfaction and extra-role behavior. Journal of Vocational Behavior, 72: 388-399.

van Knippenberg, D. 2000. Work motivation and performance: A social identity perspective. Applied Psychology, 49: 357-371.

van Knippenberg, D. 2003. Intergroup relations in organizations. In M. A. West, D. Tjosvold, \& K. G. Smith (Eds.), International handbook of organizational teamwork and cooperative working: 381-399. Chichester, UK: Wiley.

van Knippenberg, D., De Dreu, C. K. W., \& Homan, A. C. 2004. Work group diversity and group performance: an integrative model and research agenda. Journal of Applied Psychology, 89: 1008-1022.

van Knippenberg, D., \& van Schie, E. 2000. Foci and correlates of organizational identification. Journal of Occupational and Organizational Psychology, 73: 137-147.

Van Ophem, H., Stam, P., \& van Praag, B. 1999. Multichoice logit: Modeling incomplete preference rankings of classical concerts. Journal of Business \& Economic Statistics, 17: 117-128.

Walter, J., Kellermanns, F. W., Floyd, S. W., Veiga, J. F., \& Matherne, C. 2013. Strategic alignment: A missing link in the relationship between strategic consensus and organizational performance. Strategic Organization, 11: 304-328.

Wenzel, M., Mummendey, A., \& Waldzus, S. 2007. Superordinate identities and intergroup conflict: The ingroup projection model. European Review of Social Psychology, 18: 331-372.

West, C. T., \& Schwenk, C. R., Jr. 1996. Top management team strategic consensus, demographic homogeneity and firm performance: A report of resounding nonfindings. Strategic Management Journal, 17: 571-576.

Wooldridge, B., \& Floyd, S. W. 1989. Research notes and communications strategic process effects on consensus. Strategic Management Journal, 10: 295-302.

Wooldridge, B., \& Floyd, S. W. 1990. The strategy process, middle management involvement, and organizational performance. Strategic Management Journal, 11: 231-241.

Wrzesniewski, A., \& Dutton, J. E. 2001. Crafting a job: Revisioning employees as active crafters of their work. Academy of Management Review, 26: 179-201. 